\title{
Visual Outcome of Corneal Laceration Repair in a Tertiary Hospital, Southwestern, Nigeria
}

\author{
Olusola Joseph OMOTOYE ${ }^{1}$, Iyiade Adeseye AJAYI ${ }^{2}$, Kayode Olumide AJITE ${ }^{3}$, Samuel Ayokunle DADA ${ }^{4}$, \\ Emmanuel Chinwedu ABAH ${ }^{5}$
}

${ }^{1}$ Dr. Olusola Joseph OMOTOYE, Consultant Ophthalmologist, ${ }^{2}$ Dr. Iyiade Adeseye AJAYI, Consultant Ophthalmologist, ${ }^{3}$ Dr. Kayode Olumide AJITE, Consultant Ophthalmologist; ${ }^{4}$ Dr. Samuel Ayokunle DADA, Consultant Nephrologist, Department of Medicine, Ekiti State University Teaching Hospital, Ado Ekiti, Nigeria. ${ }^{5}$ Dr. Emmanuel Chinwedu, Ophthalmic Resident; ${ }^{1,2,3,5}$ Authors are affiliated with Department of Ophthalmology, Ekiti State University Teaching Hospital, Ado Ekiti, Nigeria.

Corresponding Author: Dr. Olusola Joseph Omotoye, Department of Ophthalmology, Ekiti State University Teaching Hospital, Ado Ekiti, Nigeria, E-mail: layoshol@yahoo.com

\begin{abstract}
Objective: This study aimed at assessing the visual outcome of patients that had corneal laceration repair with their influencing factors in order to reduce the significant consequential vision loss in the patients. Design: A cross sectional study. Subjects: All patients who had open globe injury and corneal repair procedures. Methods: Clinic and theatre records of all patients who had open globe injury and corneal repair procedures between January 2015 and July 2017 were retrieved. Demographic characteristics, main eye complaints, duration of symptoms, laterality, presenting visual acuity, corneal repair procedures and six weeks post operative visual acuity were obtained from the records. All patients who had open globe injury but had primary Enucleation or Evisceration were excluded from the study. Data obtained were recorded and analyzed using Statistical Package for Social Sciences (SPSS) version 25. Results: Forty patients had corneal repair procedure constituting $22.2 \%$ of all ophthalmic procedures. There were $30(75.0 \%)$ males and $10(25.0 \%)$ females. At the oculoplastic clinic, majority of the patients $33(82.5 \%)$ presented with monocular blindness $(\mathrm{VA}<3 / 60)$ while, only the dependent group of patients $5(12.5 \%)$ presented with normal visual acuity $\geq 6 / 18$. There was $10 \%$ improvement in vision after corneal repair procedure. There was positive correlation between pre-operative visual acuity and post-operative visual acuity. Conclusion: Corneal laceration injury has a relatively high incidence with a $10 \%$ improvement in vision after corneal repair procedure. Timely presentation, prompt clinical assessment and early intervention when non-avoidable ocular injury occurs remain the key to a good functional post-operative vision.
\end{abstract}

Key words: Cornea, Globe, Injury, Outcome, Vision.

\section{Introduction}

Corneal laceration results from injury to the globe which is a significant cause of visual loss and remains a serious public health problem [1]. Open globe injury is an ophthalmologic emergency and requires definitive management by an ophthalmologist [1]. Over $90 \%$ of these open globe injuries are thought to be preventable [2]. Penetrating eye injury accounts for 3.81 injuries per 100,000 annually in USA [3] the incidence of open globe injury in adults was $3.40 / 100,000$ in Turkey [4] while in a tertiary hospital in Nigeria, incidence of 4.50/100,000 was reported during a communal clash [5].

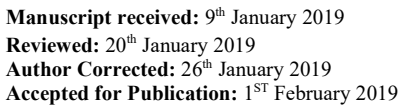




\section{Original Research Article}

disruption, damage to the macular and or the optic nerve [8], time lag between injury and surgery and relative afferent pupillary defect (RAPD) [2]. The study was carried out to assess the visual outcome of patients that had corneal laceration repair with their influencing factors in order to reduce the significant consequential visual morbidity in the patients.

\section{Material and Methods}

Design: A cross sectional study was conducted in a tertiary centre which is an urban hospital with an established, strategically located tertiary eye care as the eye of the hospital. It runs subspecialty eye facility weekly in Glaucoma, Oculoplasty, Retina and General Ophthalmology.

Subjects: All patients who had open globe injury and corneal repair procedures.

Sample collection: Data was obtained from clinic and theatre records of all Ophthalmic Plastic patients from either self-referral, General Ophthalmology clinics within the centre or other centres within and outside the state who had open globe injury and corneal repair procedures between January 2015 and July 2017. Demographic characteristics, main eye complaints, duration of symptoms, laterality, presenting visual acuity and corneal repair procedures and six weeks post-operative visual acuity were obtained from the records. Visual acuity were categorized with $\geq 6 / 18$ as normal, $<6 / 18$ to $>3 / 60$ as visual impairment and $<3 / 60$ as blindness. Infants were classified as either blind or believed not to be blind.

Exclusion criteria: All patients who had open globe injury but had primary Enucleation or Evisceration.

Ethical approval was obtained from the institution's ethical review committee though data collection did not directly involve patient's participation.

Analysis- Data obtained were recorded and analyzed using Statistical Package for Social Sciences (SPSS) version 25. Means (Standard deviations) were used to describe the distributions of continuous variables. Categorical variables were described in Percentages. Comparisons of categorical data were performed with the use of Pearson's chi-square test. Furthermore, the Bivariate correlation statistics was done to evaluate the strength of association between preoperative visual acuity and postoperative six weeks visual acuity. $P<$ 0.05 was considered statistically significant.

\section{Results}

Forty patients (40) had corneal repair procedure constituting $22.2 \%$ of all ophthalmic procedures and $2.7 \%$ of all ocular surgeries done during this period. There were 30(75.0\%) males and $10(25.0 \%)$ females with a male to female ratio of 3:1 $(\chi 2=10.000, \mathrm{df}=1, \mathrm{p}=0.002)$. The ages ranged from 6 months to 52 years with mean age of $21.67 \pm 15.2$ years. All the cases were unilateral with $25(62.5 \%)$ occurring in the right eye and $15(37.5 \%)$ in the left eye.

The proportions of males were higher in all age groups except at age group 10-19years where females had a higher proportion. Table 1

Table-1: Age group and Sex Distribution

\begin{tabular}{|c|c|c|}
\hline Age Group(years) & Male n (\%) & Female n (\%) \\
$0-9$ & $9(64.3)$ & $5(35.7)$ \\
$10-19$ & $2(40.0)$ & $3(60.0)$ \\
$20-29$ & $7(87.5)$ & $1(12.5)$ \\
$30-39$ & $5(83.3)$ & $1(16.7)$ \\
$40-49$ & $6(100.0)$ & $0(0)$ \\
$50-59$ & $1(100.0)$ & $0(0)$ \\
Total & $\mathbf{3 0}(\mathbf{7 5 . 0})$ & $\mathbf{1 0}(\mathbf{2 5 . 5})$ \\
\hline
\end{tabular}

Figure 1 showed majority of the patients presented at oculoplastic clinic with blindness VA $<3 / 60$ except the dependant group of patients which presented with normal visual acuity $\geq 6 / 18$.

Figure 2 Showed that monocular blindness $(\mathrm{VA}<3 / 60)$ was found in $33(82.5 \%)$ of patients while $5(12.5 \%)$ of the patients presented with normal vision ( $\mathrm{VA} \geq 6 / 18)$. 


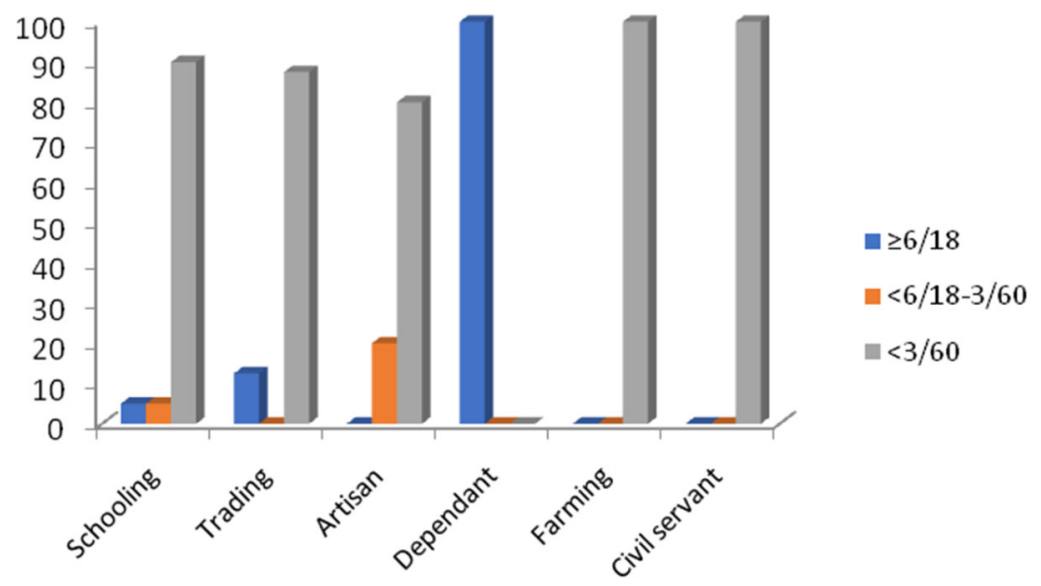

Figure-1: Occupation of Patients versus Presenting Visual Acuity

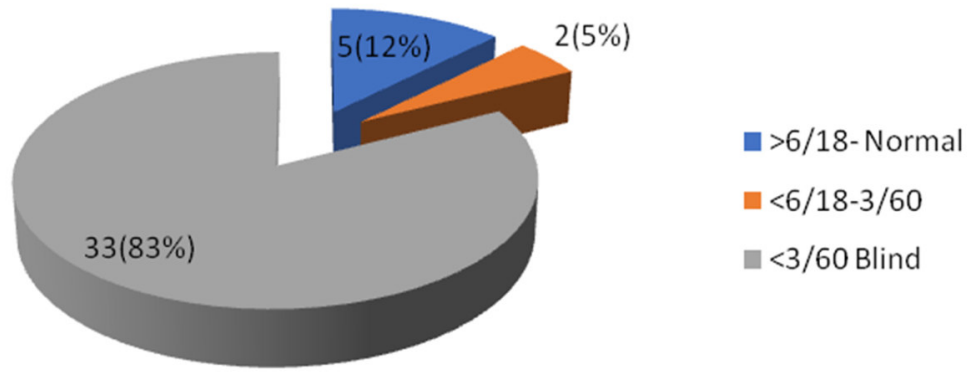

Figure-2: Presenting Visual Acuity of Patients with Corneal Laceration

Table-2: Visual Outcome of Corneal Repair Procedure

\begin{tabular}{|c|c|c|}
\hline Vision & VA1n (\%) & VA2 n (\%) \\
$\geq 6 / 18$ & $5(12.5)$ & $8(20.0)$ \\
$<6 / 18-3 / 60$ & $2(5.0)$ & $3(7.5)$ \\
$<3 / 60$ & $33(82.5)$ & $29(72.5)$ \\
TOTAL & $40(100)$ & $40(100)$ \\
\hline
\end{tabular}

*VA1=Presenting visual acuity, VA2= Final visual acuity after 6weeks

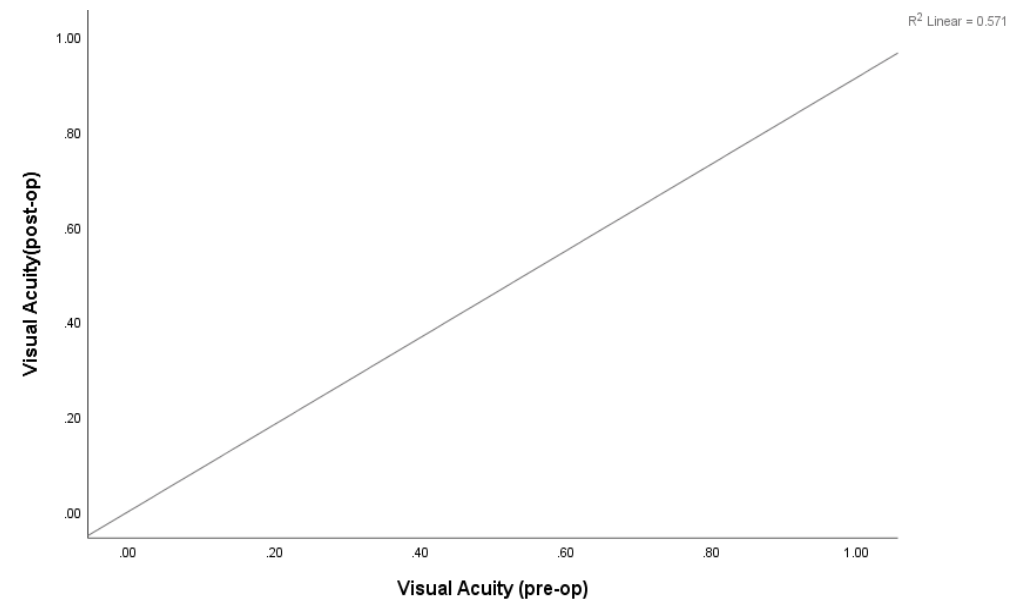

Figure-3: Bivariate Correlation graph of Pre-operative VA and 6weeks Post-operative VA 
Table 2 showed that the proportion of patients that had improved vision after corneal repair procedure increased from 7 $(17.5 \%)$ to $11(27.5 \%)$ after six weeks of follow up while blindness reduced from 33 (82.5\%) to 29 (72.5\%). Figure 3 showed a positive correlation between pre-operative visual acuity and post-operative visual acuity with a correlation coefficient of $57 \%(\mathrm{R} 2$ Linear $=0.571)$.

\section{Discussion}

Open globe injuries are a major cause of monocular blindness though largely preventable [2]. The standard procedure of carrying out primary surgical repair following corneal lacerations in an open globe injury to restore the structural integrity of the globe formed over one fifth of oculoplastic procedures in this subspecialty clinic during this period. Unless the globe was ruptured and completely disorganized beyond repair, the meticulous procedures were performed by the skilled ophthalmic surgeons after pain-staking and prompt clinical assessments of the patients. Open globe injury has a relatively high incidence in this clinic despite exclusion of all patients that had severely damaged and disorganized globe injury who had primary Enucleation or Evisceration, although lower than a reported minor ophthalmic plastic procedurein Northern part of the country [9] and some other individual procedures[5,10].

Khatry et al reported that over $75 \%$ of patients with severe ocular injuries had lacerating injuries in Nepal [11]. In addition, there may even be underrepresentation of total number of patients as reported in Adeoye study in southwestern Nigeria [5] as some patients that have multiple systemic injuries from communal clashes or road traffic accident might present in the other department like Neurosurgery in another centres [5].

One of the multiple intraocular surgical procedures to be performed was repair of the corneal laceration using microsurgical techniques in order to salvage some useful vision [2].

Amongst other procedures done were lid and scleral repair, anterior chamber wash-out, iris repair/abscission and anterior vitrectomy. These procedures should be meticulously done as soon as the patients present to the ophthalmologist. It was reported that as high as $55 \%$ of patients that had open globe injury that were offered pars plana vitrectomy had a favorable visual outcome in their study [12]. The hospital management is thus advised to employ a vitreo-retinal surgeon in this hospital so that our patients can enjoy that management procedure. Furthermore, for a better visual outcome, unnecessary delay from hospital bureaucracy vis-à-vis payment of operation fees before procedure should be reduced to minimize the consequential visual morbidity from the already injured eye.
This can be achieved by government extending the coverage of National Health Insurance policy to the entire citizen thereby reducing out of pocket expenses for the patients.

The male preponderance in this study is similarly found in many studies [5,13-17]. Reasons for the male preponderance have been well documented in the literature being that males are more involved in riskladened activities than their female counterparts [16,18]. A young age group was also observed to present with corneal laceration for which repair was done in this study as seen in the literature $[1,5,7]$. The incidence in the young age group could be reduced as documented in the literature by engaging in parental education and closer supervision of children in and outside the home and the use of protective eye wear in sports activities [7].

Majority of the patients presented at oculoplastic clinic with blindness $\mathrm{VA}<3 / 60$ except the dependent group of patients which presented with normal visual acuity $\geq 6 / 18$. The proportion of monocular blindness was over $4 / 5^{\text {th }}$ of all patients that presented with corneal laceration in the subspecialty clinic. This is in accordance with the earlier report that stated that ocular trauma is a major cause of monocular blindness and visual impairment worldwide [1,5]. It therefore remains a significant cause of vision loss [1].

Although majority of the patients presented with blindness, it was noteworthy that all the dependent group of patients with corneal laceration presented with normal vision compared with the other groups of patients. This could be partly due to the fact that they enjoyed better protection or better catered for by the caregiver and enjoyed closer supervision than other group of patients thus presented earlier to the eye facility. The above reason has not been proven to be among the factors documented in the literature to predict the vision outcome after an open globe injury which include mechanism or type of injury, preoperative visual acuity, time lag between injury and surgery and size and location of the wound [18]. If these above adduced reasons could be established in a future study, efforts should be put in place to sustain this observation so as to reduce the visual morbidity resulting from home or school-related eye injury. 


\section{Original Research Article}

This study showed that the proportion of patients that had improved vision after corneal repair procedure increased minimally after six weeks of follow up. There was a positive correlation between pre-operative visual acuity and the final visual acuity after six weeks of postoperative period. This was similar to some other studies where final visual acuity after surgical repair of open globe injuries was influenced by the preoperative visual acuity $[18,19]$.

Presenting visual acuity in turn depends on severity of injury. It has been documented that eyes have a greater risk of injury during conflict than other parts of the body due to preferential exposure of the face in combat [12].

This emphasizes the fact that prevention of ocular injury should be prioritized as prevention is cheaper and better than treatment. Blindness prevention campaign should therefore be incorporated into the primary eye care to minimize ocular morbidity in eye injury. A wellstructured or planned eye health education workshop should be carried out at the local government area to teach the other health workers on eye health promotion so that the message will be widely disseminated to the rural dwellers.

Furthermore, prompt recognition and ophthalmologic interventions are essential to maximizing functional outcome [20]. Though many badly injured eyes despite micro-surgical procedures might not be salvaged [2], timely presentation, prompt clinical assessment and early interventions [21] when non-avoidable ocular injury occurs remain key to good functional postoperative vision. Finally, ocular injury can be prevented by wearing of protective spectacles at work and through frequent health education to reduce the incidence of eye injury that might result to losing the eye [22].

\section{Conclusion}

Corneal laceration injury has a relatively high incidence. There was $10 \%$ improvement in vision after corneal repair procedure with a positive correlation between pre-operative visual acuity and post-operative visual acuity.

All the dependent group of patients with corneal laceration presented with normal vision compared with the other groups of patients who presented with some degrees of visual impairment or blindness. Timely presentation, prompt clinical assessment and early intervention when non-avoidable ocular injury occurs remain the key to a good functional post-operative vision.

\section{What this study add to existing knowledge}

1. Corneal laceration injury which is an open globe injury has a relatively high incidence in this tertiary referral centre.

2. There was $10 \%$ improvement in vision after corneal repair procedure with a positive correlation between pre-operative visual acuity and post-operative visual acuity.

3. All the dependent group of patients with corneal laceration presented with normal vision compared with the other groups of patients who presented with some degrees of visual impairment or blindness.

4. Local government health workers should have a well-structured workshop on eye health promotion programmes for effective dissemination to the rural dwellers.

5. Painstaking and meticulous repair of corneal repair following open globe injury could result in $10 \%$ improvement in postoperative vision.

\section{Authors' Contributions}

1. OMOTOYE OJ: Conceived the original idea and preparation ofthe manuscript

2. AJAYIIA: Involved in manuscript preparation, drafting and critically revising the work

3.AJITE KO: Involved in manuscript preparation and critically revising the work

4. DADA SA: Involved in manuscript preparation, analysis and critically revising the work

5. ABAH EC: Data collection, drafting and critically revising the work

Funding: Nil, Conflict of interest: Nil

Permission from IRB: Yes

\section{References}

1. Batur M, Seven E, Esmer O, et al. Epidemiology of Adult Open Globe Injury. J Craniofac Surg. 2016 Oct;27(7):1636-1641.

2. Rahman $\mathrm{I}^{1}$, Maino A, Devadason D, et al. Open globe injuries: factors predictive of poor outcome. Eye (Lond). 2006 Dec;20(12):1336-41. Epub 2005 Sep 23.

3. Gilbert C, Soong H, Hirst L. A two-year prospective study of penetrating ocular trauma at the Wilmer Ophthalmological Institute. Annals of ophthalmology. 1987;19(3):104-6.

4. Kim J, Marbella A, Knippers J. Incidence of Open Globe Injuries in Wisconsin for 2002. Investigative Ophthalmology \& Visual Science. 2006;47(13):3959-. 


\section{Original Research Article}

5. Adeoye A, Olateju S, Soetan E. Communal conflictrelated ocular trauma. Nigerian Journal of Clinical Practice. 2002;5(1):1-4.

6. Sternberg Jr P. Prognosis and outcomes for penetrating ocular trauma. Eye Trauma St Louis: Mosby Year Book. 1991:238-41.

7. Hooi SH, Hooi ST. Open-globe injuries: the experience at Hospital Sultanah Aminah, Johor Bahru. Med J Malaysia. 2003 Aug;58(3):405-12.

8. Groess1 S, Nanda SK, Mieler WF. Assault-related penetrating ocular injury. Am J Ophthalmol. $1993 \mathrm{Jul}$ 15;116(1):26-33.

9. Odugbo O, Mpyet C, Wade P, Adenuga O, Adejoh M. An audit of minor ophthalmic surgical interventions in a tertiary eye care facility in Northern Nigeria. Journal of the West African College of Surgeons. 2014;4(2):26.

10. Eze BI. Audit of ophthalmic surgical interventions in a resource-deficient tertiary eye care facility in SubSaharan Africa. J Health Care Poor Underserved. 2013 Feb; 24 (1):197-205. doi: 10.1353/hpu.2013.0013.

11. Khatry SK, Lewis AE, Schein OD, et al. The epidemiology of ocular trauma in rural Nepal. Br J Ophthalmol. 2004 Apr;88(4):456-60.

12. Sobaci G, Mutlu FM, Bayer A, et al. Deadly weapon-related open-globe injuries: outcome assessment by the ocular trauma classification system. Am J Ophthalmol. 2000 Jan;129(1):47-53.

13. Omolase CO, Omolade EO, Ogunleye OT, et al. Pattern of ocular injuries in owo, Nigeria. J Ophthalmic Vis Res. 2011 Apr;6(2):114-8.
14. Jahangir T, Butt NH, Hamza U, Tayyab H, Jahangir S. Pattern of presentation and factors leading to ocular trauma. Pak J Ophthalmol. 2011;27(2):96-102.

15. Okoye O, Maduka-Okafor F, Eze B. Open globe injuries. Nigerian Journal of Surgical Sciences. 2007;17(1):37-42.

16. Ajayi IA, Ajite KO, Omotoye OJ. Epidemiological survey of traumatic eye injury in a Southwestern Nigeria tertiary hospital. Pakistan Journal of Ophthalmology. 2014;30(3):138.

17. Smith D, Wrenn K, Stack LB. The epidemiology and diagnosis of penetrating eye injuries. Acad Emerg Med. 2002 Mar;9(3):209-13.

18. Agrawal R, Rao G, Naigaonkar R, et al. Prognostic factors for vision outcome after surgical repair of open globe injuries. Indian $\mathrm{J}$ Ophthalmol. 2011 NovDec;59(6):465-70. doi: 10.4103/0301-4738.86314.

19. Cillino S, Casuccio A, Di Pace F, et al. A five-year retrospective study of the epidemiological characteristics and visual outcomes of patients hospitalized for ocular trauma in a Mediterranean area. BMC Ophthalmol. 2008 Apr 22;8:6. doi: 10.1186/14712415-8-6.

20. Kuhn F, Morris R, Witherspoon CD, et al. A standardized classification of ocular trauma. Graefes Arch Clin Exp Ophthalmol. 1996 Jun;234(6):399-403.

21. Adeoye AO, Onakpoya OH. Indication for eye removal in Ile-Ife, Nigeria. Afr J Med Med Sci. 2007 Dec;36(4):371-5.

22. Joseph OO, Adeseye AI, Oluseye AO. Patients' Satisfaction with Destructive Eye Surgery in Ophthalmic Plastic Clinic in a Tertiary Institution.

\section{How to cite this article?}

Olusola Joseph OMOTOYE, Iyiade Adeseye AJAYI, Kayode Olumide AJITE, Samuel Ayokunle DADA, Emmanuel Chinwedu ABAH. Visual Outcome of Corneal Laceration Repair in a Tertiary Hospital, Southwestern, Nigeria. Trop J Ophthalmol Otolaryngol.2019;4(1):13-18.doi:10.17511/jooo.2019.101.03 